\title{
The impact of colonoscopy indication on polyp detection rate
}

\author{
Fadi Abu Bakera*, Amir Marib*, Deepash Hosadurgc, Muhammed Sukia , Baruch Ovadiaa, Oren Gala, \\ Yael Kopelamna
}

Hillel Yaffe Medical Center, Hadera, Israel; Nazareth EMMS Hospital, Israel; University College London Hospital, UK

${ }^{\star}$ Fadi Abu Baker and Amir Mari contributed equally to this manuscript

\begin{abstract}
Background Adenoma/polyp detection rates are considered to be among the most important quality indicators of colonoscopy and are key measures of a quality procedure. However, they are designed for use in the screening setting and are not amenable to other colonoscopy indications. Little is known about their significance in other colonoscopy indications. We aimed to evaluate the impact of the various indications on polyp detection rate (PDR).

Methods This was a retrospective, single-center study. Electronic reports of index colonoscopy procedures with adequate bowel preparation over a 10-year period were reviewed. Patients were divided into 7 groups based on the study indication. PDR was determined for each group and was compared to that of a control group, the screening indication group. Adjustment was made for potential confounders such as age, sex, and procedural setting.

Results A total of 13,054 patients were considered suitable for the study. PDR was greatest in the positive fecal occult blood test group, with a value of $33.1 \%(\mathrm{P}<0.01)$. Overall, the remaining groups showed similar PDRs compared with screening (22.1\% vs. $20.4 \%$; $\mathrm{P}=0.15)$. This trend persisted in a multivariate analysis, which showed the odds ratio in the positive fecal occult blood test group to be significantly higher, with a value of $1.955(1.759-2.172, \mathrm{P}<0.001)$ compared with the screening group.

Conclusion PDR was highest for the positive fecal occult blood test indication, but was not affected significantly by most indications. Further randomized studies are warranted to confirm these findings and help calculate recommended thresholds for "overall" PDR.
\end{abstract}

Keywords Polyp detection rate, quality indicator, non-screening colonoscopy

Ann Gastroenterol 2019; 32 (3): 1-5

\section{Introduction}

Colorectal cancer (CRC) is one of the most common tumors and is the third leading cause of cancer-related mortality for men and women in the United States [1]. Fortunately, it is one of the most preventable malignancies [2-5]. This depends on

Department of a Gastroenterology and Hepatology, Hillel Yaffe Medical Center, Hadera, Israel; Affiliated to the Technion Faculty of Medicine, Haifa, Israel (Fadi Abu Baker, Muhammed Suki, Baruch Ovadia, Oren Gal, Yael Kopelamn); 'bastroenterology, Nazareth EMMS Hospital; Affiliated with the Faculty of Medicine, Bar Illan University (Amir Mari); ' University College London Hospital (Deepash Hosadurg)

\section{Conflict of Interest: None}

Correspondence to: Abu baker Fadi, Gastroenterology and Hepatology Department, Hillel Yaffe Medical Center, Hashalom Street, Hadera, Israel, e-mail: fa_fd@hotmail.com

Received 22 January 2019; accepted 11 March 2019; published online 4 Apri. 2019

DOI: https://doi.org/10.20524/aog.2019.0374 the adequate detection and removal of potentially precancerous polyps and early-stage CRC lesions. In this regard, colonoscopy is the preferred CRC prevention method, serving as an optimal tool for CRC screening and surveillance [6-11].

Several quality indicators (QI) have been established to maximize the effectiveness of colonoscopy in detecting pre-malignant lesions and to propose reliable markers with consistently high-quality endoscopic practice [12]. The primary colonoscopy QI is the adenoma detection rate (ADR). It is defined as the percentage of average-risk screening colonoscopies in which one or more conventional adenomas are detected. ADR has been demonstrated to be directly associated with interval cancer (i.e., a cancer diagnosed between the time of scheduled screening/surveillance studies) [7,12-14]. Though an invaluable indicator, ADR is not readily available from colonoscopy reports, as it requires integration of endoscopy and pathology records. Moreover, it ignores the serrated polyp pathway, increasingly recognized as a precursor for CRC development $[15,16]$.

Therefore, polyp detection rate (PDR) has been proposed as a more feasible and practical QI and a surrogate for ADR. It is defined as the proportion of screening colonoscopy procedures 
in which at least one polyp is removed. PDR has the advantage of simple calculation from colonoscopy reports, and was shown to correlate well with ADR in several studies [17-20]. Similarly to ADR, PDR may be affected by patient demographics, bowel preparation quality, specific endoscopist's performance, and withdrawal time [21-24].

Both ADR and PDR are designed for use in the screening setting only and are not amenable to other colonoscopy indications [12]. Despite the fact that a large percentage of colonoscopy procedures are performed for non-screening indications, reliable QI for the endoscopist's performance in the non-screening setting are limited. In this regard, PDR may be an eligible QI candidate, but this has not been fully studied or validated. The impact of different indications for colonoscopy on PDR was addressed in this study by determining PDR for various colonoscopy indications and comparing this with a matched control group, the screening group.

\section{Patients and methods}

In this retrospective study we included a large cohort of patients who underwent colonoscopy over a 10-year period at the gastroenterology department of the Hillel Yaffe medical center, a university-affiliated hospital in Israel. All patients' data were collected from our department's electronic record system. Only patients older than 50 years who were undergoing first-time colonoscopy and had full details of demographic information (age, sex), procedural setting (inpatient/outpatient), procedure's indication, quality of bowel preparation, depth of examination, and endoscopic findings were included in the final analysis. All procedures in the study were sedation-mediated using propofol or benzodiazepines and opiates. For bowel preparation, all patients received a split-dose, polyethylene glycol-based (MoviPrep $\odot$, Meroken $\odot$ ) or sodium picosulphate and magnesium citrate-based (Picolax@) regimens. For the assessment of bowel preparation, a uniform scale with 5 categories was used. This scale is based on an institutional score used nationally for many years. Bowel preparation is then accordingly classified into adequate (excellent/good/acceptable) or inadequate (poor/moderate) preparations.

Patients with inadequate bowel preparation, past colonoscopy, incomplete examination, or a history of personal CRC or other abdominal tumors were excluded.

Six different groups of study indications were created as follows: anemia, positive results for fecal occult blood test (FOBT), constipation or altered bowel habits, family history of polyps or colorectal cancer, rectal bleeding, and weight loss. Multivariate analysis was performed to adjust for potential confounders affecting PDR, including age, sex and setting.

We calculated PDR among the different groups and compared the findings with patients who underwent colonoscopy for screening as a control group.

The local institutional Helsinki ethics board approved the study and granted exemption from informed consent as patients were receiving standard care without relation to the study. Data collection did not influence medical practice.

\section{Statistical analysis}

Descriptive statistics in terms of mean, standard deviation and percentage were used for all the parameters in the study. Differences between groups were evaluated using Fisher's exact test for categorical parameters and the $t$-test for quantitative parameters. Multivariate logistic regression analysis was used to determine the effect of the independent parameters associated with PDR, in terms of odds ratio and $95 \%$ confidence interval (95\%CI). A value of $\mathrm{P}<0.05$ was consider as significant. All statistical analyses were conducted using SPSS version 25 .

\section{Results}

A total of 26,210 procedures in the study period were reviewed. Of these 13,156 (50.2\%) did not meet the inclusion criteria and were excluded as follows: 5123 (19.5\%) had inadequate bowel preparation, 1331 (5\%) had an incomplete exam, and 3394 (12.9\%) were under age 50. In addition, $3308(12.6 \%)$ procedures were excluded as they were performed for heterogenic indications other than those specified in the study, mainly for surveillance procedures but also for suspected imaging findings, inflammatory bowel disease suspicion or follow up, elevated tumor markers, abdominal pain, or other unspecified indication.

Thus, 13,054 patients completed full colonoscopies with adequate bowel preparation and were considered suitable for inclusion in the study: $51 \%$ of the patients were male and $49 \%$ were female. The mean age was $63.1 \pm 9.3$ (male) and 63.6 \pm 9.7 (female).

The cohort was divided into 7 groups based on the indication of the study. The largest group was for rectal bleeding, with 3029 patients $(24.4 \%)$, while the smallest group was for weight loss, with 504 patients (4.1\%). The other groups included constipation or change in bowel habits (2211 patients, $17.8 \%$ ), family history of polyps or CRC $(2109,17.0 \%)$, anemia (2085, $16.8 \%)$, positive FOBT result $(2082,16.8 \%)$, and screening (control group) $(1034,8.3 \%)$. Table 1 shows the baseline characteristics of the patients according to indication group.

In a univariate analysis (Fig. 1 and Table 2), PDR was greatest in the positive FOBT group with a value of $33.1 \%(\mathrm{P}<0.01)$. The lowest rate was seen in the screening group, which we

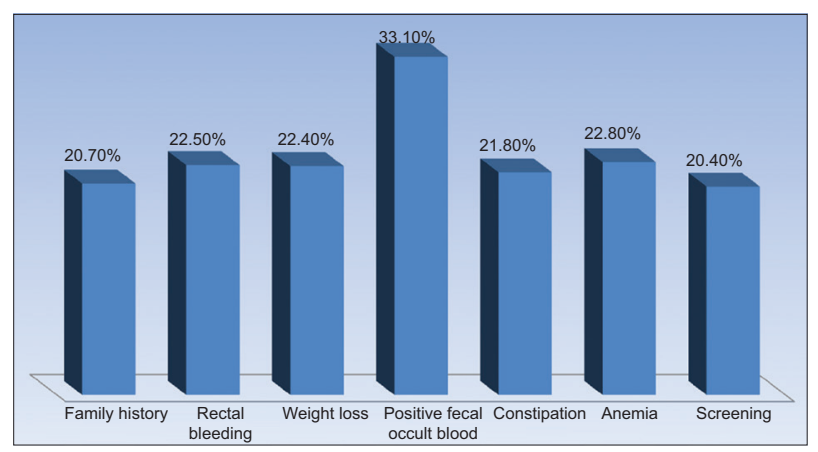

Figure 1 Polyp detection rate according to colonoscopy indication 
Table 1 Baseline characteristics for patients in each indication group

\begin{tabular}{lcccc}
\hline Indication group & Patients & Male sex & Age (years) & Outpatient setting \\
\hline Screening & 1034 & $595(57.5 \%)$ & $59.9 \pm 7.00$ & $1006(97.3 \%)$ \\
Anemia & 2085 & $978(46.9 \%)$ & $68.5 \pm 10.5$ & $1452(69.6 \%)$ \\
Constipation & 2211 & $1049(47.4 \%)$ & $65.4 \pm 9.7$ & $2033(91.9 \%)$ \\
Positive FOBT & 2082 & $1039(49.9 \%)$ & $62.6 \pm 8.1$ & $2025(97.3 \%)$ \\
Weight loss & 504 & $226(44.8 \%)$ & $67.9 \pm 10.7$ & $381(75.6 \%)$ \\
Rectal bleed & 3029 & $1664(54.9 \%)$ & $62.5 \pm 9.7$ & $2632(86.9 \%)$ \\
Family history & 2109 & $1066(50.5 \%)$ & $58.9 \pm 6.7$ & $2082(98.7 \%)$ \\
\hline
\end{tabular}

FOBT, fecal occult blood test

Table 2 Polyp detection rate (PDR) in each indication group. Univariate and multivariate analysis

\begin{tabular}{|c|c|c|c|c|c|c|c|}
\hline \multirow[t]{2}{*}{ Indication } & \multicolumn{4}{|c|}{ Univariate PDR } & \multicolumn{3}{|c|}{${ }^{\star}$ Multivariate PDR } \\
\hline & PDR rate & P-value & OR & $95 \% \mathrm{CI}$ & P-value & OR & 95\%CI \\
\hline Screening & $211(20.4 \%)$ & Ref & Ref & Ref & Ref & Ref & Ref \\
\hline Anemia & $476(22.8 \%)$ & $\mathrm{P}=0.13$ & 1.15 & $0.96-1.38$ & $\mathrm{P}<0.01$ & 0.78 & $0.69-0.88$ \\
\hline Constipation & $483(21.8 \%)$ & $\mathrm{P}=0.35$ & 1.09 & $0.91-1.31$ & $\mathrm{P}<0.01$ & 0.85 & $0.76-0.95$ \\
\hline Positive FOBT & $690(33.1 \%)$ & $\mathrm{P}=0.001$ & 1.93 & $1.62-2.31$ & $\mathrm{P}<0.01$ & 1.95 & $1.75-2.17$ \\
\hline Weight loss & $113(22.4 \%)$ & $\mathrm{P}=0.38$ & 1.12 & $0.98-1.46$ & $\mathrm{P}=0.11$ & 0.83 & $0.67-1.04$ \\
\hline Rectal bleeding & $682(22.5 \%)$ & $\mathrm{P}=0.16$ & 1.13 & $0.95-1.34$ & $\mathrm{P}=0.074$ & 091 & $0.83-1.00$ \\
\hline Family history of polyps or colorectal cancer & $436(20.7 \%)$ & $\mathrm{P}=0.88$ & 1.01 & $0.84-1.22$ & $\mathrm{P}=0.27$ & 0.93 & $0.83-1.05$ \\
\hline
\end{tabular}

took to be the control, with a value of $20.4 \%$. The remaining groups showed no significantly high rate of polyp detection. The anemia group had a PDR of $22.8 \%$ (476 patients), rectal bleeding $22.5 \%$ (682 patients), weight loss $22.4 \%$ (113 patients), constipation/change in bowel habits $21.8 \%$ (483 patients), family history of polyp or CRC $20.7 \%$ (436 patients).

We carried out a multivariate analysis to account for the variability caused by age, sex and setting for each indication. The most significant finding was that, even when these factors were controlled, the odds ratio in the positive FOBT group was significant, with a value of 1.955 (95\%CI 1.759-2.172, $\mathrm{P}<0.001$ ) compared with the control PDR screening group that we took as a reference. The other indication groups had values very similar to the control group and were not translated into a higher detection of polyps. Interestingly, the constipation and anemia groups even showed a slightly lower but significant PDR (Table 2).

\section{Discussion}

In this study we investigated the impact of different indications for colonoscopy on PDR and compared this to a matched control group, which we took as the screening indication group. Although ADR and PDR play an important role in terms of quality indicators, they were designed for use and are exclusively applicable in the screening setting [25].
However, expanding PDR use beyond the screening procedures by calculating overall ADR/PDR, inclusive of all colonoscopy indications, may better reflect the performance of endoscopists in daily clinical practice. Surprisingly, very few studies in the literature have addressed the effect of a procedure's indication on PDR. Nonetheless, interest has been growing recently in deriving a simplified overall ADR and the creation of minimum ADR thresholds [26].

In the current study, we showed that, except for the positive FOBT indication group, PDR was not increased significantly by a procedure's indication compared with screening $(22 \%$ vs. $20.4 \%$; $\mathrm{P}=0.15$ ), even after a multivariate analysis with adjustment for different possible confounders. Moreover, slightly lower but significant PDRs were demonstrated in the anemia and constipation groups on a multivariate analysis. These finding are in concordance with a study by Boroff et al [27], who showed that the ADR for colonoscopies performed for bleeding or anemia did not differ from that of screening colonoscopy, while other non-surveillance procedures were associated with significantly lower ADRs compared with screening. A study by Kahi et al [28] demonstrated that when ADR was stratified by colonoscopy indication, it was highest for surveillance, followed by screening then diagnostic.

In patients undergoing colonoscopy for positive FOBT, however, PDR was prominently and significantly greater compared with the screening group, with an odds ratio of 1.955 (95\%CI 1.759-2.172, $\mathrm{P}<0.001)$. Similar findings were demonstrated by Cubiella et al [29], who found that the 


\section{Summary Box}

\section{What is already known:}

- Adenoma and polyp detection rates (ADR/PDR) are premier quality indicators for colonoscopy procedures

- ADR/PDR were designed for use in a screening setting only

- Little is known about effect of procedure indication on ADR/PDR

\section{What the new findings are:}

- PDR is highest for the positive fecal occult blood test indication

- Other indications for colonoscopy were not significantly associated with a higher PDR compared to screening

- Calculating overall ADR/PDR for both screening and non-screening procedures may be feasible, but more studies are warranted

thresholds for performance should be considerably higher in the population with positive fecal immunochemical testing than in a screening colonoscopy population. Likewise, several studies have demonstrated that ADR was significantly higher in surveillance colonoscopies compared with screening $[15,27,28]$. In our study, however, we did not include patients with surveillance: the inclusion criteria were limited to first-time procedures, as PDR/ADR is calculated solely in this setting.

Taken together, our findings suggest that the target value recommended for PDR/ADR could be used reliably for non-screening indications, while higher targets for PDR are warranted in colonoscopies performed for indications of positive FOBT or surveillance. Further randomized trials are required to confirm these findings.

One of the strengths of our study is the high number of participants involved, as well as the inclusion of multiple different indications reflecting real world practice. This is one of the largest studies to evaluate the value of PDR as a viable tool for quality assessment under different colonoscopy indications. Our study has limitations inherent in its retrospective nature. Moreover, other possible factors that may have impacted PDR, such as withdrawal time and variable endoscopist experience, could not be determined and were not included. Other limitations could be that the exclusion criteria meant that only patients over the age of 50 , with a first-time procedure, adequate bowel preparation and complete examination were included. This would make the results less applicable to the general population, leading to reduced external validity. Applicability would also be affected by the fact that this was a single-center study that would need to be replicated by other centers. Although ADR is extensively studied and widely used, in the current study we used PDR in preference to ADR, as its calculation can be more feasible in clinical practice and there is no need to integrate endoscopic and histological findings.

In conclusion, in a non-surveillance setting PDR is highest for positive FOBT but was not significantly altered when compared with other indications. Further studies to confirm these findings and help calculate recommended thresholds for "overall" PDR are warranted.

\section{References}

1. Siegel R, Desantis C, Jemal A. Colorectal cancer statistics, 2014. CA Cancer J Clin 2014;64:104-117.

2. Cronin KA, Lake AJ, Scott S, et al. Annual Report to the Nation on the Status of Cancer, part I: National cancer statistics. Cancer 2018; 124:2785-2800.

3. Fitzmaurice C, Allen C, Barber RM, et al; Global burden of disease cancer collaboration. Global, regional, and national cancer incidence, mortality, years of life lost, years lived with disability, and disability-adjusted life-years for 32 cancer groups, 1990 to 2015: a systematic analysis for the Global Burden of Disease Study. JAMA Oncol 2017;3:524-548.

4. Jemal A, Bray F, Center MM, Ferlay J, Ward E, Forman D. Global cancer statistics. CA Cancer J Clin 2011;61:69-90.

5. Center MM, Jemal A, Ward E. International trends in colorectal cancer incidence rates. Cancer Epidemiol Biomarkers Prev 2009;18: 1688-1694.

6. Winawer SJ, Fletcher RH, Miller L, et al. Colorectal cancer screening: clinical guidelines and rationale. Gastroenterology 1997;112: 594-642.

7. Corley DA, Jensen CD, Marks AR, et al. Adenoma detection rate and risk of colorectal cancer and death. N Engl J Med 2014;370: 1298-1306.

8. Carlsson G, Petrelli NJ, Nava H, Herrera L, Mittelman A. The value of colonoscopic surveillance after curative resection for colorectal cancer or synchronous adenomatous polyps. Arch Surg 1987;122: 1261-1263.

9. Rex DK, Lehman GA, Hawes RH, Ulbright TM, Smith JJ. Screening colonoscopy in asymptomatic average-risk persons with negative fecal occult blood tests. Gastroenterology 1991;100:64-67.

10. Brenner H, Hoffmeister M, Arndt V, Stegmaier C, Altenhofen L, Haug U. Protection from right- and left-sided colorectal neoplasms after colonoscopy: population-based study. J Natl Cancer Inst 2010; 102:89-95.

11. Brenner H, Chang-Claude J, Seiler CM, Rickert A, Hoffmeister M. Protection from colorectal cancer after colonoscopy: a populationbased, case-control study. Ann Intern Med 2011;154:22-30.

12. Rex DK, Schoenfeld PS, Cohen J, et al. Quality indicators for colonoscopy. Gastrointest Endosc 2015;81:31-53.

13. Kaminski MF, Regula J, Kraszewska E, et al. Quality indicators for colonoscopy and the risk of interval cancer. N Engl J Med 2010;362: 1795-1803.

14. Kaminski MF, Wieszczy P, Rupinski M, et al. Increased rate of adenoma detection associates with reduced risk of colorectal cancer and death. Gastroenterology 2017;153:98-105.

15. Anderson JC, Butterly LF, Goodrich M, Robinson CM, Weiss JE. Differences in detection rates of adenomas and serrated polyps in screening versus surveillance colonoscopies, based on the New Hampshire Colonoscopy Registry. Clin Gastroenterol Hepatol 2013;11:1308-1312.

16. Obuch JC, Pigott CM, Ahnen DJ. Sessile serrated polyps: detection, 
eradication, and prevention of the evil twin. Curr Treat Options Gastroenterol 2015;13:156-170.

17. Williams JE, Le TD, Faigel DO. Polypectomy rate as a quality measure for colonoscopy. Gastrointest Endosc 2011;73:498-506.

18. Gohel TD, Burke CA, Lankaala P, et al. Polypectomy rate: a surrogate for adenoma detection rate varies by colon segment, gender, and endoscopist. Clin Gastroenterol Hepatol 2014;12:1137-1142.

19. Francis DL, Rodriguez-Correa DT, Buchner A, Harewood GC, Wallace M. Application of a conversion factor to estimate the adenoma detection rate from the polyp detection rate. Gastrointest Endosc 2011;73:493-497.

20. Williams JE, Holub JL, Faigel DO. Polypectomy rate is a valid quality measure for colonoscopy: results from a national endoscopy database. Gastrointest Endosc 2012;75:576-582.

21. Simmons DT, Harewood GC, Baron TH, et al. Impact of endoscopist withdrawal speed on polyp yield: implications for optimal colonoscopy withdrawal time. Aliment Pharmacol Ther 2006;24: 965-971.

22. Harewood GC, Sharma VK, de Garmo P. Impact of colonoscopy preparation quality on detection of suspected colonic neoplasia. Gastrointest Endosc 2003;58:76-79.

23. Barclay RL, Vicari JJ, Doughty AS, Johanson JF, Greenlaw RL. Colonoscopic withdrawal times and adenoma detection during screening colonoscopy. N Engl J Med 2006;355:2533-2541.

24. Barret M, Boustiere C, Canard JM, et al; Société Française d'Endoscopie Digestive. Factors associated with adenoma detection rate and diagnosis of polyps and colorectal cancer during colonoscopy in France: results of a prospective, nationwide survey. PLoS One 2013;8:e68947.

25. Rex DK, Petrini JL, Baron TH, et al; ASGE/ACG Taskforce on Quality in Endoscopy. Quality indicators for colonoscopy. Am J Gastroenterol 2006;101:873-885.

26. Hassan C, Repici A, Rex DK. FITting ADR to colonoscopy indication. United European Gastroenterol J 2017;5:148-152.

27. Boroff ES, Disbrow M, Crowell MD, Ramirez FC. Adenoma and polyp detection rates in colonoscopy according to indication. Gastroenterol Res Pract 2017;2017:7207595.

28. Kahi CJ, Vemulapalli KC, Johnson CS, Rex DK. Improving measurement of the adenoma detection rate and adenoma per colonoscopy quality metric: the Indiana University experience. Gastrointest Endosc 2014;79:448-454.

29. Cubiella J, Castells A, Andreu M, et al; COLONPREV study investigators. Correlation between adenoma detection rate in colonoscopy- and fecal immunochemical testing-based colorectal cancer screening programs. United European Gastroenterol J 2017;5: 255-260. 